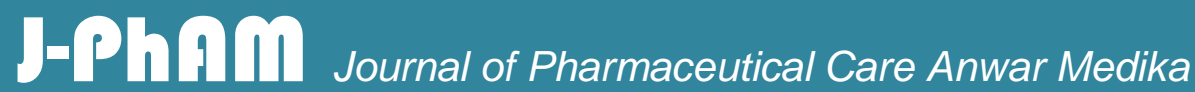

Artikel Penelitian

\section{Aktivitas Antioksidan Ekstrak Etil Asetat Daun Kelor (Moringa Oleifera L)}

\author{
Rosalina Y. Kurang ${ }^{1}$, Faryda V. Lamma Koly ${ }^{2}$, Diana I. Kafolapada ${ }^{3}$, \\ Program Studi Kimia, Fakultas Matematika dan Ilmu Pengetahuan Alam, Universitas Tribuana \\ Kalabahi \\ Email: rosalinayuliana89@gmail.com
}

\begin{abstract}
Abstrak: Tanaman kelor (Moringa oliefera L) merupakan salah satu tanaman yang tersebar luas di Indonesia. Salah satu daerah yang memiliki tanaman ini adalah pulau Alor dengan jenis daun kelor yaitu daun kelor yang beraroma/wangi dan tidak beraroma. Pemanfaatan daun kelor belum banyak diketahui oleh masyarakat. Penelitian ini bertujuan untuk mengetahui aktivitas antioksidan daun kelor wangi (Moringa oliefera L). Metode yang digunakan yaitu metode ekstraksi dan metode DPPH. Hasil analisis menunjukkan bahwa ekstrak etil asetat daun kelor wangi (Moringa oliefera L) mengandung golongan senyawa flavonoid, terpenoid dan fenolik. Hasil uji antioksidan menunjukan bahwa ekstrak etil asetat daun kelor wangi (Moringa oliefera L) memiliki aktivitas antioksidan yang sangat kuat dengan nilai $\mathrm{IC}_{50}$ sebesar 14,301 ppm.
\end{abstract}

Kata kunci : Moringa oliefera L, fitokimia, antioksidan, DPPH

Abstract: Moringa oliefera $L$ is one of the most plants in Indonesia. One area has this plant is Alor island with the type of Moringa leaves are flavorful and not flavorful. The use of Moringa leaves is not widely known by the public. The aim of this research is to determine the antioxidant activity of moringa leaves flavorful. The method used is the extraction method and the DPPH method. The results of the analysis showed that ethyl acetate extract of Moringa oliefera L, contained compounds group of flavonoids, terpenoids and phenolic. Antioxidant activity test showed that the ethyl acetate extract of Moringa oliefera L have a strong antioxidant activity with an IC 50 14,301 ppm.

Keywords : Moringa oliefera L, phytochemicals, antioxidant, DPPH 


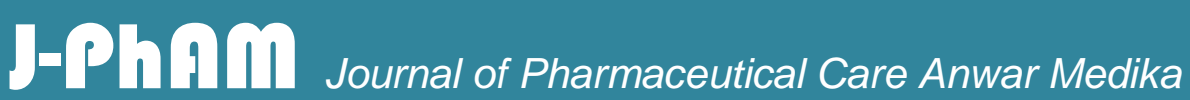

\section{Artikel Penelitian}

\section{PENDAHULUAN}

Tanaman kelor (Moringa oleifera L) merupakan salah satu tanaman yang tersebar luas Indonesia. Tanaman ini memiliki manfaat dan khasiat pada semua bagian tanaman baik daun, batang, akar maupun biji.

Berbagai bagian dari tanaman kelor bertindak sebagai stimulan jantung dan peredaran darah, memiliki antitumor, antipiretik, antiepilepsi, antiinflamasi, antiulser, diuretik, antihipertensi, menurunkan kolesterol, antioksidan, antidiabetik, antibakteri dan anti-jamur [1]. Zat aktif yang terkandung dalam daun kelor yang berpotensi sebagai antioksidan adalah berbagai jenis vitamin (A, C, E, K, B1, B2, B3, B6, flavonoid, alkaloid, saponin, tanin, dan terpenoid [2].

Antioksidan merupakan zat yang mampu memperlambat atau mencegah proses oksidasi. Antioksidan juga dapat didefinisikan sebagai senyawa-senyawa yang melindungi sel dari efek berbahaya radikal bebas oksigen reaktif [3]. Antioksidan bekerja dengan cara mendonorkan satu elektronnya kepada senyawa lain yang bersifat antioksidan sehingga aktivitas senyawa oksidan tersebut bisa dihambat. Senyawa ini memiliki berat molekul kecil, tetapi mampu menginaktifkan berkembangnya reaksi oksidasi dengan cara mencegah terbentuknya radikal [3].

Salah satu daerah yang memiliki tanaman kelor terbesar yaitu pulau Alor - Nusa Tenggara Timur. Tanaman kelor yang dikenal terdiri dari dua jenis yaitu tanaman kelor yang beraroma dan yang tidak beraroma. Masyarakat memanfaatkan daun tanaman kelor sebagai sayuran khas daerah dan juga digunakan untuk pereda rasa sakit yang disebabkan oleh suntikan, namun masyarakat belum mengetahui khasiat lain dari daun tumbuhan kelor itu sendiri. Kandungan senyawa kimia dan bioaktivitas tanaman kelor yang tumbuh di daerah Alor belum pernah diteliti dan mengingat kondisi geografis masing-masing daerah berbeda kemungkinan ada perbedaan dalam kandungan senyawa kimia yang terdapat pada tanaman kelor. Oleh karena itu penelitian ini dilakukan dengan tujuan untuk memberikan informasi kepada masyarakat, terkait kandungan kimia daun kelor beraroma yang dapat menghambat aktivitas radikal bebas dan kemampuannya sebagai bahan antioksidan alami. 


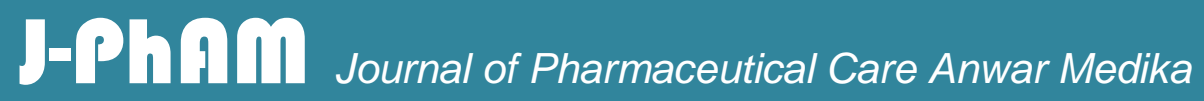

\section{Artikel Penelitian}

\section{METODE}

\section{Bahan dan alat}

Bahan-bahan yang digunakan adalah daun kelor yang beraroma, metanol $\left(\mathrm{CH}_{3} \mathrm{OH}\right)$, asam sulfat $\left(\mathrm{H}_{2} \mathrm{SO}_{4}\right)$ pekat, asam klorida $(\mathrm{HCl})$, Besi (III) klorida $\left(\mathrm{FeCl}_{3}\right) 1 \%$, serbuk magnesium (Mg), raksa (II) klorida $\left(\mathrm{HgCl}_{2}\right)$, 1,1-difenil-2-pikrilhidrazyl (DPPH), aquades, kloroform. Alat-alat yang digunakan adalah spektrofotometer UV-Vis, timbangan analitik, rotary vakum evaporator, aluminium foil, kertas saring, vortex inkubator, lempeng KLT, tabung reaksi, peralatan gelas.

\section{Prosedur kerja}

\section{Preparasi sampel}

Sampel yang digunakan adalah daun kelor yang beraroma. Sampel dibersihkan dari pengotor lalu dikering-anginkan dan dihaluskan sampai diperoleh serbuk.

\section{Ekstraksi}

Sebanyak 71 gr serbuk daun kelor wangi diekstraksi secara maserasi menggunakan pelarut etil asetat sebanyak 1L selama 1 hari, setelah itu disaring dengan kertas saring. Filtrat yang diperoleh kemudian dievaporasi sehingga diperoleh ekstrak pekat daun kelor.

\section{Uji fitokimia}

\section{Pengujian Flavonoid.}

Ekstrak pekat sebanyak 1 gr dimasukkan ke dalam tabung reaksi, kemudian ditambahkan $5 \mathrm{~mL}$ etanol 96\%, setelah larut ditambahkan 3 tetes $\mathrm{HCl}$ pekat, kemudian ditambahkan 15 gr serbuk Mg. Terbentuknya warna merah atau merah muda menunjukan adanya flavonoid [4]. 


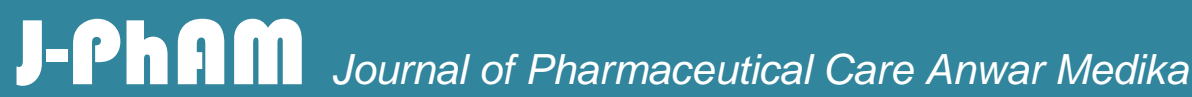

\section{Artikel Penelitian}

\section{Pengujian Alkaloid}

Ekstrak pekat sebanyak 1 gr dimasukkan ke dalam tabung reaksi, setelah itu ekstrak ditambahkan 3 mL kloroform kemudian diaduk. Setelah larut ditambahkan 3 tetes pereaksi meyer. Terbentuknya endapan putih menunjukkan adanya alkaloid [4].

\section{Pengujian Terpenoid}

Ekstrak pekat sebanyak 1 gr ekstrak dimasukkan ke dalam tabung reaksi kemudian ditambahkan $2 \mathrm{~mL}$ kloroform. Setelah larut, ditambahkan $3 \mathrm{~mL} \mathrm{H} \mathrm{SO}_{4}$. Terbentuknya warna cokelat menunjukkan adanya terpenoid [4].

\section{Pengujian Fenolik.}

Ekstrak pekat sebanyak 1 gr ekstrak dimasukkan ke dalam tabung reaksi, kemudian ditambahkan 10 tetes $\mathrm{FeCl}_{3}$ 1\%. Terbentuknya warna hijau, merah, ungu, biru, atau hitam pekat menunjukkan adanya fenol [4].

\section{Uji Antioksidan}

Pengujian sifat antioksidan diawali dengan, pembuatan larutan DPPH $6 \times 10^{-5} \mathrm{M}$. Sebanyak 1,182 mg DPPH dilarutkan ke dalam $50 \mathrm{~mL}$ metanol. Pembuatan larutan uji 100 ppm dilakukan dengan melarutkan $10 \mathrm{mg}$ sampel (ekstrak daun kelor) ke dalam $100 \mathrm{~mL}$ metanol. Kemudian diencerkan menjadi 50 ppm, 40 ppm, dan 30 ppm, 20 ppm dan 10 ppm. Larutan uji dipipet sebanyak 33,33 $\mu \mathrm{L}$ dan kemudian dimasukkan ke dalam tube yang terlindung dari cahaya, kemudian ditambahkan 1mL DPPH. Campuran larutan tersebut diaduk menggunakan alat vortex mixer selama 10 detik atau hingga homogen. Selanjutnya, larutan diinkubasi pada suhu $30^{\circ} \mathrm{C}$ selama 30 menit. Larutan DPPH radikal akan berubah warna dari ungu menjadi kuning pucat selama proses reduksi oleh antioksidan. Penurunan absorbansi ini diukur dengan spektrofotometer UV pada panjang gelombang $515 \mathrm{~nm}$. Aktivitas penghambat radikal dapat dihitung dengan menggunakan rumus pada persamaan (1). 


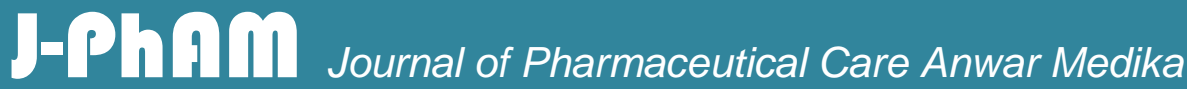

Artikel Penelitian

Inhibition rate $(\%)==\frac{\mathrm{Ab}-\mathrm{As}}{\mathrm{Ab}} \times 100$

$\mathrm{Ab}$ : absorbansi blanko

As : absorbansi senyawa uji

Setelah diperoleh presentasi inhibisi dari masing-masing konsentrasi, selanjutnya hasil perhitungan dimasukkam ke dalam persamaan regresi dengan konsentrasi ekstrak (ppm) sebagai absis (sumbu $\mathrm{x}$ ) dan nilai \% inhibisi (antioksidan) sebagai koordinatnya (sumbu y). Aktivitas antioksidan dinyatakan dengan inhibisi concentration $50 \%$ yaitu konsentrasi larutan uji yang dapat merendam radikal DPPH sebanyak 50\%, [5], [6].

\section{HASIL DAN PEMBAHASAN}

Hasil analisis fitokimia ekstrak etil asetat daun kelor (Moringa oleifera L) ditunjukkan pada Tabel 1.

Tabel 1. Hasil uji fitokimia ekstrak etil asetat daun kelor

\begin{tabular}{lllc}
\hline No & Metabolit sekunder & Pengamatan & Kesimpulan \\
\hline 1 & Flavonoid & Terbentuk warna kuning & + \\
2 & Alkaloid & Tidak tebentuk warna putih tetapi & - \\
& & terbentuk warna coklat & \\
3 & Terpenoid & Terbentuk warna kuning kecoklatan & + \\
4 & Fenolik & Terbentuk warna hijau kehitaman & + \\
\hline Keterangan : & & \\
$+=$ terdapat golongan senyawa & \\
$-=$ tidak terdapat golongan senyawa &
\end{tabular}

Berdasarkan Tabel 1. diketahui bahwa kandungan golongan senyawa yang ada pada ekstrak etil asetat daun kelor (Moringa oliefera L) yaitu flavonoid, terpenoid, dan fenolik, sedangkan golongan senyawa alkaloid tidak terdeteksi.

Pengujian terhadap golongan senyawa flavonoid menunjukkan hasil yang positif yaitu terbentuknya warna kuning. Warna yang dihasilkan merupakan hasil reaksi antara $\mathrm{HCl}$ dengan logam $\mathrm{Mg}$. Senyawa flavonoid akan dioksidasi oleh $\mathrm{Mg}^{2+}$ dengan membentuk kompleks dengan ion magnesium. 


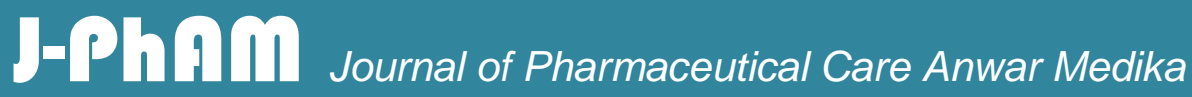

\section{Artikel Penelitian}

Polihidroksi dari flavon akan direduksi oleh logam magnesium dalam asam klorida sehingga membentuk garam flavilium. Flavonoid merupakan senyawa yang mengandung dua cincin aromatik dengan gugus hidroksil. Mekanisme reaksi uji flavonoid dapat di lihat pada Gambar 1.

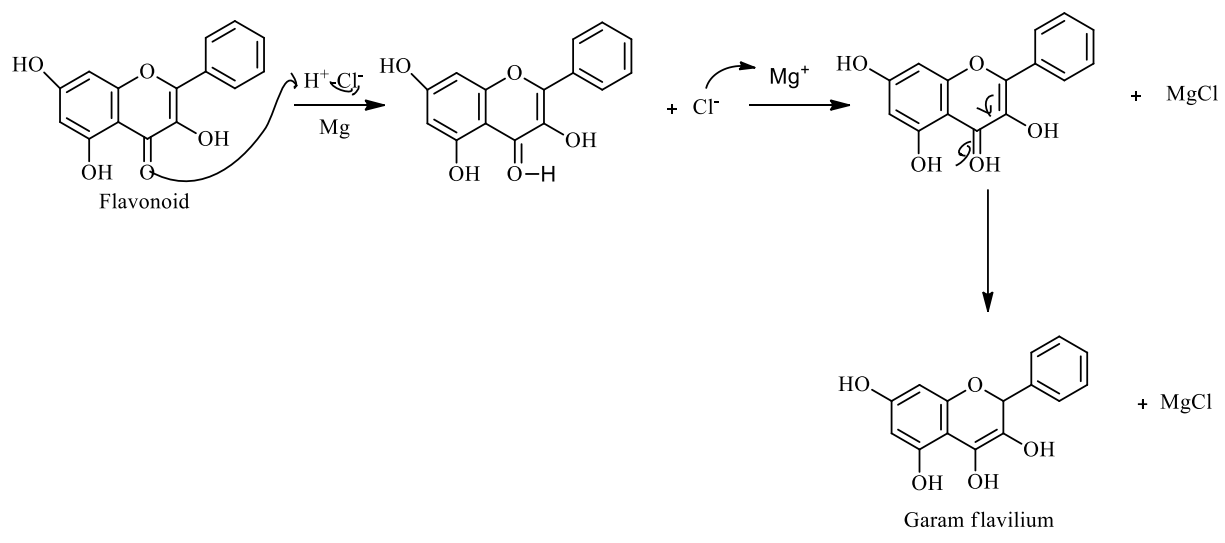

Gambar 1. Reaksi uji flavonoid

Golongan senyawa terpenoid pada ekstrak etil asetat daun kelor (Moringa oliefera L) menunjukkan hasil positif dengan terbentuknya warna kuning kecoklatan. Warna yang terbentuk merupakan reaksi antara asam sulfat yang ditambahkan ke dalam ekstrak yang telah diencerkan dengan kloroform. Prinsip reaksi dalam mekanisme reaksi uji terpenoid adalah kondensasi atau pelepasan $\mathrm{H}_{2} \mathrm{O}$ dan penggabungan dengan karbokation. Reaksi ini diawali dengan proses asetilasi gugus hidroksil menggunakan asam asetat anhidrida. Gugus asetil yang merupakan gugus pergi yang baik akan lepas, sehingga terbentuk ikatan rangkap. Selanjutnya terjadi pelepasan gugus hidrogen beserta elektronnya, mengakibatkan ikatan rangkap berpindah. Senyawa ini mengalami resonansi yang bertindak sebagai elektrofil atau karbokation. Serangan karbokation menyebabkan adisi elektrofilik, diikuti pelepasan hidrogen. Kemudian gugus hidrogen beserta elektronnya dilepas, akibatnya senyawa mengalami perpanjangan konjugasi yang memperlihatkan munculnya warna coklat. Mekanisme terbentuknya warna tersebut dapat dilihat pada Gambar 2. 


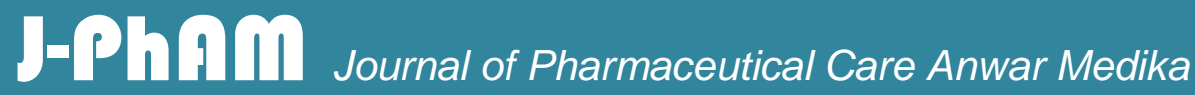

\section{Artikel Penelitian}

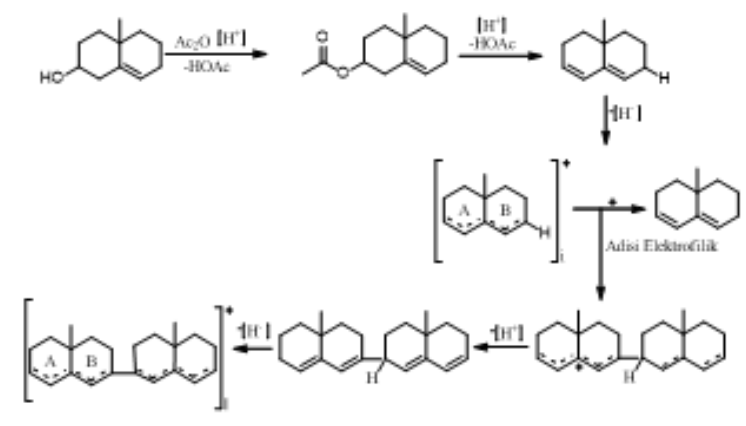

Gambar 2. Mekanisme reaksi uji terpenoid

Hasil uji terhadap golongan senyawa fenol menunjukkan hasil positif dengan terbentuknya warna hijau kehitaman. Warna yang terbentuk dikarenakan gugus fenol pada senyawa fenolik membentuk kompleks dengan ion $\mathrm{Fe}^{3+}$ dari $\mathrm{FeCl}_{3}$. Senyawa fenolik adalah senyawa yang terdiri dari cincin aromatik dengan gugus hidroksi $(-\mathrm{OH})$ satu atau lebih.

$$
\mathrm{FeCl}_{3}(\mathrm{aq})+6 \mathrm{ArOH}(\mathrm{aq}) \longrightarrow 6 \mathrm{H}^{+}(\mathrm{aq})+3 \mathrm{Cl}^{-}(\mathrm{aq})+\left|\mathrm{Fe}(\mathrm{OAr})_{6}\right|^{3-}(\mathrm{aq})
$$

Gambar 3. Mekanisme reaksi uji fenolik

Antioksidan merupakan senyawa yang dapat menghambat reaksi oksidasi dengan mengikat radikal bebas dan molekul yang sangat reaktif sehingga kerusakan sel dapat dihambat. Hasil reaksi antara DPPH dengan senyawa antioksidan dapat diketahui melalui perubahan warna DPPH dari ungu pekat menjadi kuning yang terjadi akibat donasi proton yang dilakukan oleh antioksidan bahan alam kepada DPPH. Perubahan warna ini dijadikan sebagai patokan pengukuran pada spektrofotometer cahaya tampak [7]. Aktivitas antioksidan dari ekstrak etil asetat daun kelor diuji menggunakan spektrofotometer UV-Vis berdasarkan penurunan nilai absorbansi DPPH setelah diberi sampel uji terhadap kontrol pada setiap kenaikan konsentrasi. Data absorbansi ekstrak etil asetat terhadap reduksi DPPH dengan variasi konsentrasi yang diperoleh kemudian dihitung persentase penghambatan menggunakan rumus dan diperoleh hasilnya, seperti yang ditunjukkan pada Tabel 2. 


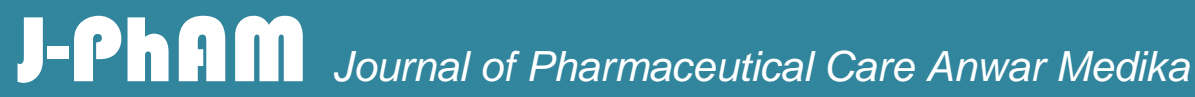

\section{Artikel Penelitian}

Tabel 2. Data Absorbansi ekstrak etil asetat daun kelor (Moringa oliefera $\mathbf{L}$ )

\begin{tabular}{llccclc}
\hline $\begin{array}{l}\text { Sampel } \\
\text { Uji }\end{array}$ & $\begin{array}{l}\text { Konsentrasi } \\
(\mathrm{ppm})\end{array}$ & $\begin{array}{c}\text { Absorbansi } \\
\text { I }\end{array}$ & \multicolumn{1}{l}{ I } & III & $\begin{array}{l}\text { Absorbansi } \\
\text { rata-rata }\end{array}$ & \% Inhibisi \\
\hline Daun & 10 & 0,291 & 0,282 & 0,245 & 0,272 & 39,941 \\
kelor & 20 & 0,178 & 0,193 & 0,188 & 0,186 & 58,957 \\
& 30 & 0,125 & 0,115 & 0,121 & 0,120 & 73,494 \\
& 40 & 0,070 & 0,069 & 0,073 & 0,070 & 84,434 \\
& 50 & 0,062 & 0,060 & 0,056 & 0,059 & 86,930 \\
\hline
\end{tabular}

Setelah diperoleh presentase inhibisi dari masing-masing konsentrasi, persamaan $y=a x+$ $\mathrm{b}$ ditentukan dengan perhitungan secara regresi linear dimana $\mathrm{x}$ adalah konsentrasi (ppm) dan y adalah presentasi inhibisi sebagaimana terlihat pada Gambar 4.

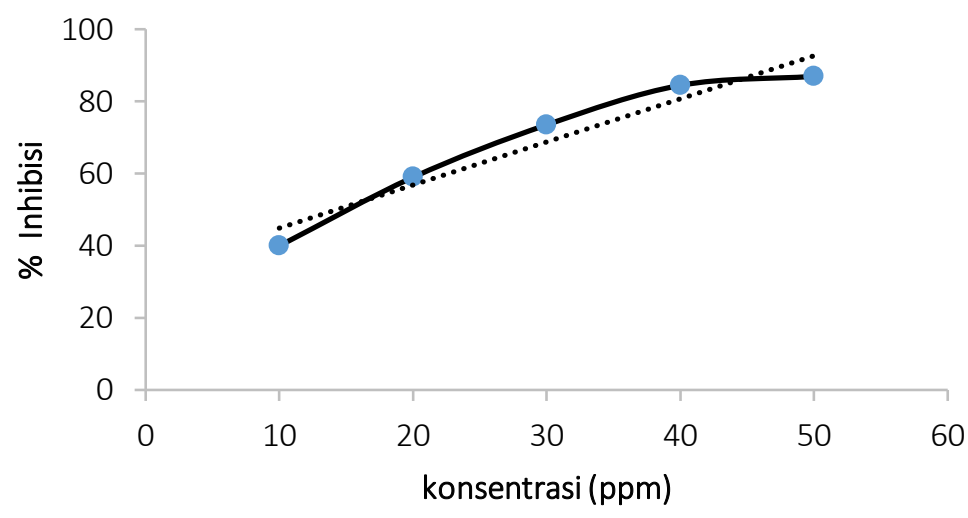

Gambar 4. Kurva regresi penetapan $\mathrm{IC}_{50}$ daun kelor

Berdasarkan hasil perhitungan, Nilai $\mathrm{IC}_{50}$ ekstrak pekat etil asetat daun kelor yaitu 14,301 ppm. Nilai $\mathrm{IC}_{50}$ ini menunjukkan bahwa ekstrak etil asetat daun kelor (Moringa oliefera L) memiliki aktivitas antioksidan yang sangat kuat [7] yaitu memiliki nilai IC $_{50}$ $<50 \mathrm{ppm}$. Tingginya aktivitas antioksidan dikarenakanekstrak etil asetat daun kelor (Moringa oliefera L) mengandung banyak senyawa fenolik dan senyawa flavonoid yang berkontribusi terhadap aktivitas antioksidan. Asam askorbat digunakan sebagai kontrol positif antioksidan dengan $\mathrm{IC}_{50} 28.266 \mathrm{ppm}$. Aktivitas antioksidan dari daun kelor beraroma (Moringa oleifera L) lebih kuat daripada asam askorbat antioksidan. 


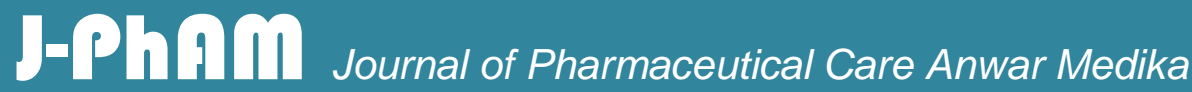

Artikel Penelitian

\section{KESIMPULAN}

Hasil penelitian menunjukkan bahwa aktivitas antioksidan daun kelor yang beraroma (Moringa oleifera $\mathrm{L}$ ) sangat kuat dengan nilai $\mathrm{IC}_{50} 14.301$ ppm sehingga dapat digunakan sebagai sumber antioksidan.

\section{UCAPAN TERIMA KASIH}

Ucapan terima kasih disampaikan kepada semua pihak yang telah membantu dalam pelaksanaan penelitian ini.

\section{DAFTAR PUSTAKA}

1. S. S. Toripah, J. Abidjulu, dan F. Wehantouw, "Aktivitas Antioksidan dan Kandungan Total Fenolik Ekstrak Daun Kelor (Moringa oleifera L)," Program Studi Farmasi FMIPA Universitas Samratulangi, Manado, 2014.

2. Kurniasih, "Khasiat dan manfaat daun kelor untuk penyembuhan berbagai penyakit," Cetakan I. Pustaka Baru Press, Yogyakarta, 2013.

3. H. M. S. Winarsi, "Antioksidan alami dan radikal bebas," Yogyakarta: Kansius, 2007.

4. C. A. Unuigbe, H. A. Okeri, O. Erharuyi, E. E. Oghenero, and D. A. Obamedo, "Phytochemical and antioxidant evaluation of Moringa oleifera (Moringaceae) leaf and seed," Journal of Pharmacy and Bioresources, vol 11, no 2, pp. 51-57, 2014.

5. B. Williams, M.E. Cuvelier, and C. Berset,"LWT Food Sci", Technol., vol 28, no 1, pp. 25-30. 1995.

6. S. Dudonńe, X. Vitrac, P. Coutière, M. Woillez, and J. M. Mérillon, , J. Agric. Food Chem., vol. 57, no. 5, pp. 1768-1774, 2009.

7. P. Molyneux, "The use of the stable free radical diphenylpicrylhydrazyl (DPPH) for estimating antioxidant activity," Songklanakarin Journal Science Technology, vol. 26, no. 2, pp. 211-219, 2004. 